\title{
Does batrachotoxin autoresistance co-evolve with toxicity in Phyllobates poison-dart frogs?
}

2 Roberto Márquez ${ }^{1,2 *}$, Valeria Ramírez-Castañeda², Adolfo Amézquita ${ }^{2}$

$3{ }^{1}$ Department of Ecology and Evolution, University of Chicago. 1101 East 57th St. Chicago, IL.

4 60637, USA

$5 \quad{ }^{2}$ Department of Biological Sciences, Universidad de los Andes. A.A. 4976, Bogotá, Colombia.

6 *Corresponding Author: rmarquezp@uchicago.edu, ORCID Id: 0000-0002-0644-3078

\section{Abstract}

8 Toxicity is widespread among living organisms, and evolves as a multimodal phenotype. Part of this

9 phenotype is the ability to avoid self-intoxication (autoresistance). Evolving toxin resistance can

10 involve fitness tradeoffs, so autoresistance is often expected to evolve gradually and in tandem with

11 toxicity, resulting in a correlation between the degrees of toxicity and autoresistance among toxic

12 populations. We investigate this correlation in Phyllobates poison frogs, notorious for secreting

13 batrachotoxin (BTX), a potent neurotoxin that targets sodium channels, using ancestral sequence

14 reconstructions of BTX-sensing areas of the muscular voltage-gated sodium channel.

15 Reconstructions suggest that BTX resistance arose at the root of Phyllobates, coinciding with the

16 evolution of BTX secretion. After this event little or no further evolution of autoresistance seems to

17 have occurred, despite large increases in toxicity throughout the history of these frogs. Our results

18 therefore provide no evidence in favor of an evolutionary correlation between toxicity and

19 autoresistance, which conflicts with previous work. Future research on the functional costs and

20 benefits of mutations putatively involved in BTX resistance, as well as their prevalence in natural

21 populations should shed light on the evolutionary mechanisms driving the relationship between

22 toxicity and autoresistance in Phyllobates frogs.

23 Key Words: Sodium channel, $\mathrm{Na}_{\mathrm{v}}$ 1.4, Dendrobatidae chemical defense, neurotoxin resistance. 


\section{Main text}

25 A wide variety of species across the tree of life accumulate toxins as defenses from predators and parasites (Edmunds 1974; Mebs 2001). Toxicity usually evolves as a multi-level phenotype, comprised of physiological, behavioral, and morphological traits involved in acquiring, storing, delivering, and resisting toxins. The ability to avoid self-intoxication, also known as autoresistance, is an important piece of this phenotypic syndrome: For toxins to represent a selective advantage their bearer must not suffer their adverse effects. Predictably, toxic organisms display multiple autoresistant phenotypes, such as specialized glands or organelles to compartmentalize toxins, or molecular changes in the toxins' targets that inhibit or decrease their effects (Daly et al. 1980; Zhou and Fritz 1994; Geffeney et al. 2005; Zhen et al. 2012; Hanifin and Gilly 2015).

Although resistance can preexist toxicity, and therefore facilitate its evolution, evolving toxin resistance often involves functional changes that can have adverse pleiotropic effects, such as changes in nerve function (e.g. Brodie and Brodie 1999; Feldman et al. 2012) or reproductive output (e.g. Groeters et al. 1994; Gassmann et al. 2009). Therefore, autoresistance is usually thought to evolve gradually and in tandem with toxicity, with low levels of resistance allowing for gradual increases in toxicity that in turn promote small increases in resistance (Dobler et al. 2011; Santos et al. 2016). However, in cases where the cost of evolving additional autoresistance is low, the evolution of toxicity and resistance can become uncoupled.

Poison frogs of the family Dendrobatidae are a promising system to study the evolution of toxicity and autoresistance. The ability to sequester defensive alkaloids from dietary sources has evolved independently multiple times in this group (Santos et al. 2003; Vences et al. 2003; Santos and Cannatella 2011), and recent studies have identified amino acid substitutions on ion-transport proteins targeted by these toxins that coincide phylogenetically with the origins of alkaloid sequestration (Tarvin et al. 2016, 2017a; Yuan and Wang 2018). Some of these changes have been shown to provide toxin resistance in vitro (Tarvin et al. 2017a; Wang and Wang 2017).

49 Within Dendrobatidae, the genus Phyllobates is unique for secreting Batrachotoxin (BTX; Märki and Witkop 1963; Myers et al. 1978), one of the most powerful neurotoxins known to science $\left(\mathrm{LD}_{50}\right.$

$51=2 \mu \mathrm{g} / \mathrm{kg}$ subcutaneous in mice; Tokuyama et al. 1968). Although several poison frog species from 52 other genera (e.g. Andinobates, Dendrobates, Oophagaa) coexist with Phyllobates (Silverstone 53 1976; Myers et al. 1978), and feed on relatively similar prey types (Toft 1981; Caldwell 1996; Arce 54 and Rengifo 2013; Osorio et al. 2015), decades of chemical work on skin extracts from more than 
5570 species of poison frogs (Daly 1998; Daly et al. 2005; Santos et al. 2016) have only found BTX 56 on Phyllobates species. This steroidal alkaloid binds to the $\boldsymbol{\alpha}$ subunit of voltage-gated sodium channels on nerve and muscle cells, reducing their affinity for $\mathrm{Na}^{+}$ions, and leaving them permanently open and unable to experience action potentials (Märki and Witkop 1963; Daly et al. 1965; Warnick et al. 1976; Strichartz et al. 1987; Wang et al. 2006). Yet, nerve and muscle membranes of Phyllobates aurotaenia and P. terribilis are essentially insensitive to the action of BTX (Albuquerque et al. 1973; Daly et al. 1980). Even captive-bred individuals that were never exposed to BTX (which is obtained from dietary sources) showed full resistance, suggesting a strong genetic component of autoresistance (Daly et al. 1980). Phyllobates species vary widely in the amount of BTX stored in the skin, ranging from almost undetectable levels ( $\sim 0-1 \mu \mathrm{g}$ per frog) in

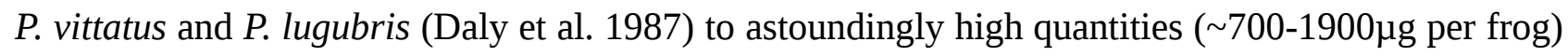
in P. terribilis (Myers et al. 1978). Furthermore, toxicity has increased at least twice in the evolutionary history of this genus, once along the branch leading to P. aurotaenia, P. bicolor and $P$. terribilis, and again in the lineage that gave rise to P. terribilis (Fig. 1; Myers et al. 1978; Daly et al. 1980, 1987), making this genus a fitting system to study the evolution of autoresistance.

Tarvin et. al. (2016) identified five amino acid replacements (A423S, I433V, A446D, V1583I, N1584T; numbering follows positions on the rat sequence) at or close to sites known to interact with BTX on the S6 segments of domains DI and IV of the muscular voltage-gated sodium channel ( $\mathrm{Na}_{\mathrm{V}} 1.4$, encoded by the SCN4A gene) of $P$. terribilis. One of them (V1583I) was also present in $P$. aurotaenia. Further work (Wang and Wang 2017) showed that only N1584T provides BTX resistance in vitro when introduced onto the rat $\mathrm{Na}_{\mathrm{v}}$ 1.4. Multiple combinations of the five substitutions were tested, and only those where N1584T was present (including N1584T alone) conferred BTX resistance.

Based on the data available from these two species, autoresistance seems to have evolved in tandem with increases in BTX levels, with $P$. terribilis having accumulated more mutations at BTX-sensing residues and greater BTX resistance than the less toxic P. aurotaenia. However, previous electrophysiological experiments have shown that nerve and muscle fibers of both P. terribilis and P. aurotaenia remain fully functional in the presence of BTX concentrations that completely inactivate the same tissues in other frogs, namely Rana pipiens (Albuquerque et al. 1973) and the dendrobatid Oophaga histrionica (cited as unpublished in Daly et al. 1980), indicating that both Phyllobates species are highly resistant to BTX. Furthermore, it was recently suggested that some 
87 sequencing artifacts (Yuan and Wang 2018), so the extent to which the SCN4A genotypes of these

88 two species differ is unclear.

89 Our aim here is to further elucidate the history of autoresistance-related mutations in Phyllobates

90 SCN4A genes, in order to evaluate the extent to which BTX autoresistance has coevolved with

91 toxicity levels in this group. To do so, we have generated SCN4A sequences from all known species

92 of Phyllobates, representing the broad spectrum of BTX variation in this group (Fig. 1), which

93 allows us to test this correlation beyond P. terribilis and aurotaenia. If autoresistance is indeed

94 correlated with BTX levels, species with higher BTX contents should exhibit more resistant

95 genotypes (e.g. with a higher number of AA changes at BTX sensing sites).

\section{Methods}

97 Combining data from previous work (Tarvin et al. 2016; Yuan and Wang 2018) and newly generated 98 sequences, we amassed a dataset of SCN4A sequences from 147 individuals of 45 species (35 99 Dendrobatoids and 10 outgroups; Tables 1 and S1), including the five known species of Phyllobates 100 (36 samples; 2-14 per species). Alkaloid profiles are available for 30 of the 35 dendrobatoids used 101 (Table 1), which allows us to confidently assume that, at least among the species sequenced BTX 102 secretion originated at the base of Phyllobates. Our dataset encompasses the S6 and P-loop 103 segments of Domains I-IV of the SCN4A gene. These regions are located on the pore of the $\mathrm{Na}_{\mathrm{V}} 1.4$ 104 channel, where BTX binds, and in vitro directed mutagenesis studies have uncovered over a dozen 105 mutations that confer BTX resistance to mamalian and insect voltage-gated sodium channels at 106 these sites (Table S2). Furthermore dendrobatid frogs, including Phyllobates have mutations related 107 to autoresistance at some of these regions (Tarvin et al. 2016). We then used ancestral sequence 108 reconstructions to investigate the evolutionary history of these segments in relation to the 109 acquisition and further increases in BTX-based toxicity among Phyllobates species.

\section{Publicly available data}

111 We downloaded publicly available SCN4A sequences for 27 dendrobatid species and seven 112 outgroup anuran species (Table S1). Sequences from seven specimens were excluded following 113 previously outlined concerns (Yuan and Wang 2018; Table S3). In addition, we extracted SCN4A 114 sequences from recently published transcriptomes of Rana pipiens (http://www.davislab.net/rana/; 115 Christenson et al. 2014) and Rhinella marina (http://gigadb.org/dataset/100374; Richardson et al. 
116 2017), and the genome of Nanorana pariekri (V2, http://gigadb.org/dataset/100132; Sun et al.

117 2015). To do so, we querried the Xenopus tropicalis $\mathrm{Na}_{\mathrm{v}} 1.4$ protein sequence

118 (ENSXTP00000031166) against each transcriptome/genome annotation with tblastn, and retained

119 the best hit. We then confirmed orthology of these sequences to SCN4A using the phylogenetic

120 approach detailed in the Sequence analysis section below.

\section{DNA sequencing}

122 We sequenced the S6 segments of the DI and DIV domains from 59 individuals of 20 species of

123 dendrobatids, 12 of which were not previously represented in public databases. DNA was extracted

124 from toe-clip, mouth swab or liver samples using Qiagen DNeasy spin columns, and SCN4A

125 fragments were amplified with primers designed based on the $X$. tropicalis sequence

126 (ENSXETG00000014235), and refined as new sequences were generated. Table S4 contains primer

127 sequences and thermal cycling protocols. PCR products were purified with ExoSap and Sanger-

128 sequenced in both directions to confirm base calls.

Transcriptome sequencing

130 We obtained a full SCN4A mRNA sequence for P. bicolor from a transcriptome assembly generated

131 for an ongoing project (Márquez, R. et al. unpublished). RNA was extracted from skin, liver, heart, 132 and muscle tissue, pooled in equimolar ratios, used to build a paired-end cDNA library, and 133 sequenced on an Illumina HiSeq 2000. After quality trimming and adapter contamination removal 134 with Trimmomatic (Bolger et al. 2014), we used Trinity (Grabherr et al. 2011) to generate an assembly. We then obtained the SCN4A sequence as described above for other species.

Sequence analysis

137 For each of the four SCN4A fragments, we aligned all homologous sequences of each species to 138 extract unique haplotypes, which were then aligned across species. From these alignments we built 139 maximum likelihood trees for each segment to search for possibly contaminated sequences (Fig. 140 S1). Next, one protein sequence was randomly selected per species for further analyses, except for 141 P. terribilis, where two alleles had amino acid differences in the DI-S6 segment, so we kept both 142 alleles. Finally, to confirm orthology of the protein sequences in our dataset (including those 143 derived from genomes and transcriptomes) to SCN4A, we aligned them to sequences of all genes in 144 the SCNA family from other vertebrates available in ENSEMBL and built a maximum likelihood 
145 tree (Fig. S3). All alignments were done using MUSCLE (Edgar 2004), and all trees were built

146 using PhyML (Guindon and Gascuel 2003; Guindon et al. 2010) under sequence evolution models

147 chosen with ProtTest (Darriba et al. 2011) or jModelTest (Darriba et al. 2012).

148 In order to infer the phylogenetic origin of amino acid substitutions, we conducted ancestral 149 sequence reconstructions in PAML (Yang 2007). Each SCN4A fragment was analyzed 150 independently under the best protein evolution model selected by ProtTest. We provided PAML 151 with a topology based on Grant et al. (2017) for dendrobatoid relationships and Pyron and Wiens 152 (2011) for outgroup relationships (Figs 2-3), and optimized its branch lengths during each ancestral 153 reconstruction. Some populations of Phyllobates aurotaenia and Epipedobates boluengeri present 154 in our dataset have been suggested to be distinct non-sister lineages by recent studies (Grant et al. 155 2017; Tarvin et al. 2017b), so we represented them as such in our phylogenies.

\section{Results}

In concordance with previous work (Tarvin et al. 2016), we found five substitutions on the S6 segments of domains DI (S429A, I433V, A445D) and DIV (V1583I, N1584T) in Phyllobates frogs (Fig. 1). According to our ancestral sequence reconstructions, three of them (S429A, I433V, V1583I) arose at the root of the genus Phyllobates, coinciding with the acquisition of BTX secretion. A445D evolved earlier, at the common ancestor of Phyllobates, Dendrobates, Ranitomeya, Andinobates, and Oophaga (i.e. the subfamily Dendrobatinae sensu Grant et al. 2006, 2017). Surprisingly, N1584T, the only substitution shown to confer BTX resistance on rat $\mathrm{Na}_{\mathrm{V}} 1.4$ channels (Wang \& Wang, 2017), was present only in a single individual of the 14 P. terribilis sequenced, and not found in any other species.

We did not find any substitutions coinciding with the origin of BTX secretion in other regions of SCN4A known to interact with BTX (i.e. DII and DIII S6 segments and DI-IV P-loops; Wang et al. 2000; Wang et al. 2001; Wang et al. 2006; Fig. 2, Fig. S2). However, our ancestral reconstructions uncovered five previously unreported substitutions in these regions (Y383F, F390Y, V748I, V774T, M777L; Fig. 3) that originated in alkaloid-sequestering clades, including the ancestor of

171 Dendrobatinae (Y383F, F390Y, V774T, M777L). Our reconstructions show that four of these 172 substitutions (Y383F, V748I, V774T, M777L) evolved more than once (although note that, despite 173 high posterior probabilities [all > 0.95], taxon sampling for DII and DIII is sparse), and Y383F and 174 M777L are present in Mantella aurantiaca, a member of a separate, distantly related radiation of 
175 poison frogs that convergently evolved the ability to sequester many of the same alkaloids present

176 in dendrobatids (Garraffo et al. 1993; Daly et al. 1996). Furthermore substitution M777L was found

177 to have occurred in parallel in five of the six frog SCNA paralogs in the recent history of 178 dendrobatids (represented by Oophaga pumilio; Rogers et al. 2018). These results suggest a 179 potential role of these five substitutions in alkaloid autoresistance that deserves further 180 investigation.

\section{Discussion}

Ancestral sequence reconstructions show that most of the amino acid substitutions in BTX-sensing regions of Phyllobates SCN4A alleles either predated or coincided with the evolution of BTX secretion, with the exception of N1584T, which seems to have evolved recently within P. terribilis, where it is still polymorphic and at low frequency. This points to a scenario where the ancestral Phyllobates $\mathrm{Na}_{\mathrm{v}} 1.4$ protein acquired autoresistance in concert with the evolution of basal levels of BTX, possibly facilitated by preexisting substitutions, and did not evolve further autoresistance as toxicity increased. In other words, our results suggest that the ancestral lineage of Phyllobates evolved sufficient BTX resistance at the $\mathrm{Na}_{\mathrm{V}} 1.4$ channel to withstand the broad range of toxicities currently present in its descendants. Once this high basal level of BTX resistance was acquired, the evolution of increased toxicity was released from the costs of increasing autoresistance.

This conflicts with the functional work of Wang and Wang (2017), who showed that neither of the three mutations coinciding with BTX secretion (S429A, I433V, V1583I; Fig. 2) nor their combinations decrease the susceptibility of the rat Nav1.4 to BTX. However, to fully understand the functional effects of these mutations on poison frog channels it is necessary to consider the genetic background on which they arose, since differences between the rat and Phyllobates channels at other sites, such as those identified in the DI P-loop and DIIS6 (Fig. 3), are likely to influence the interactions of sites 429, 433, and 1581 with BTX. For example, Tarvin et al. (2017) recently found an important effect of the genetic background (poison frog vs. human) when performing sitedirected mutagenesis tests of epibatidine resistance. Although substitutions S429A, I433V and V1583I could presumably be involved in resistance to other alkaloids, they all occur at sites of demonstrated relevance in BTX binding to Nav1.4 (Wang and Wang 1998; Vendantham and Cannon 2000) or $\mathrm{Na}_{\mathrm{v}} 1.5$ (Wang et al. 2007) channels, and mutations at these sites (different from those in Phyllobates) confer BTX resistance to mammalian channels in vitro (Wang and Wang 1998; Vendantham and Cannon 2000; Wang et al. 2007; Table S2), suggesting an important role in 
206 the evolution of BTX autoresistance. Furthermore, although none of the mutations that predated the

207 acquisition of BTX are on sites known to interact with BTX, many are close to these sites, which

208 leads us to suspect that at least some of them may have influenced the evolution of BTX 209 autoresistance, and could therefore explain the discordance with the results of Wang and Wang 210 (2017). Biochemical assays that examine the effect of mutating Phyllobates sequences back to 211 ancestral genotypes should provide insight on the functional and evolutionary implications of 212 specific mutations in BTX autoresistance. In the meantime, the molecular and physiological 213 mechanisms behind BTX resistance in Phyllobates remain an open question.

214 It is possible that N1584T played a role in the evolution of resistance to the very high levels BTX 215 found in P. terribilis, since this and other mutations at this residue confer BTX resistance to rat $216 \mathrm{Na}_{\mathrm{v}} 1.4$ channels in vitro (Wang and Wang 1999, 2017). However, the fact that this mutation occurs 217 at low frequency in P. terribilis lends little support to this hypothesis. Even the lowest amount of 218 cutaneous BTX observed in individuals of this species $(\sim 700 \mu \mathrm{g})$ is much higher than those found in any other species (Myers et al. 1978; Daly et al. 1980, 1987). Had N1584T played an important role in allowing this increase in toxicity we would expect it to have rapidly become fixed by positive selection. Further investigation of allele frequencies at this site and BTX content variation in natural populations of $P$. terribilis could help clarify the role of N1584T in the evolution of BTX autoresistance.

Evolving neurotoxin-resistant ion channels many times involves mutations at functionally important residues, which are therefore likely to have negative pleiotropic effects. For example, several mutations that make sodium channels resistant to Tetrodotoxin (TTX), a $\mathrm{Na}_{\mathrm{V}}$ blocker, have been shown to negatively impact the channel's voltage-gating and permeability/selectivity properties

228 (Chiamvimonvat et al. 1996; Pérez-García et al. 1996; Lee et al. 2011). In addition, substitutions that provide resistance to higher concentrations of TTX also tend to produce greater reductions in channel performance (Feldman et al. 2012). Therefore, populations of the TTX-resistant snake Thamnophys sirtalis appear to fine-tune their degree of TTX resistance based on the toxicity of their local newt prey (Brodie et al. 2002).

233 All known BTX-resistant mutations (Table S2) are located on or close to sites crucial to channel 234 function, such as the gating hinge (formed by residues G428, G783, G1275, S1578; Zhao et al. 235 2004), or the ion selectivity filter (i.e. the DEKA locus; residues D400, E755, K1237, A1529; 236 Backx et al. 1992; Favre et al. 1996), which could promote a similar correlation in BTX-resistant 237 Phyllobates sodium channels. Our results, nonetheless, provide no evidence in favor of this 
238

239

240

241

242

243

244

245

246

247

248

249

250

251

252

253

254

255

256

257

258

259

260

261

262

263

264

265

266

267

scenario. This could be due to several reasons. For example, it is possible that increased resistance has evolved in more toxic lineages via alternative mechanisms, such as toxin modification or sectorization. The fact that isolated nerves and muscles of $P$. terribilis and $P$. aurotaenia resist high levels of BTX (Albuquerque et al. 1973; Daly et al. 1980), however, makes this an unlikely scenario. Another (non-exclusive) possibility is that the combination of mutations S429A, I433V, and V1583I may provide high BTX resistance at a low functional cost, and that this genotype arose through an accessible mutational pathway, reducing the extent of selection against highly autoresistant genotypes in low-toxicity individuals. Additional studies that address the functional effects of these mutations in terms of BTX resistance and sodium channel/muscle performance should disentangle this issue.

Finally, our data also contribute to the understanding of the general patterns of autoresistance evolution in poison frogs, which accumulate many different toxic alkaloids. We inferred several mutations evolving at the roots of alkaloid-defended clades (e.g. Y383F, 445D, V774T, V777L), while others appear later within these clades, in closely related species with similar alkaloid profiles (e.g. S429A, V433I). This pattern is compatible with a scenario involving initial adaptation to a basal toxin profile followed by (and possibly allowing for) further diversification and increased complexity of chemical defense (e.g. more diverse alkaloid profiles) among toxic clades (Santos et al. 2016; Tarvin et al. 2016). Many of these changes occurred in parallel between alkaloid-bearing lineages, even dendrobatids and mantellids, which diverged 150 MYA (Kumar et al. 2017). Such parallelisms may be due to strong functional constraints on sodium channel evolution, although other explanations such as historical contingency can not be discarded (Wright 1932; Dean and Thornton 2007; Stern and Orgogozo 2009).

Overall, our results suggest that Phyllobates poison frogs evolved BTX-resistant Na 1.4 sodium channels in concert with the ability to secrete this toxin, and that the basal level of BTX resistance was high enough to support toxicity increases throughout the evolution of the genus without evolving further autoresistance. Future studies integrating biochemistry, physiology and population genetics are needed to illuminate the functional and evolutionary mechanisms driving the evolution of BTX resistance in these frogs' sodium channels, especially the functional effects of SCN4A mutations in relation to the tradeoff (or absence thereof) between BTX resistance and sodium channel performance. 


\section{Acknowledgements}

269 We thank Chris R. Feldman, Jorge A. Molina, Andrew J. Crawford, and Mohammad A. Siddiq for 270 insightful comments and suggestions, Valentina Gómez-Bahamón and Daniel R. Matute for 271 comments on the manuscript, Ralph A. Saporito and for clarifications about poison frog alkaloid 272 profiles, Rebecca D. Tarvin for sharing unpublished results, and Álvaro Hernandez for assistance 273 with transcriptome sequencing. This work was supported by a Seed Grant from the Faculty of 274 Sciences at Universidad de los Andes to R.M., a Basic Sciences Grant from the Vicerectory of 275 Research of the same institution to A.A. and R.M., and NSF Doctoral Dissertation Improvement 276 Grant (DEB-1702014) to R.M. and Marcus R. Kronforst. R.M. was partially supported by a 277 Fellowship for Young Researchers and Innovators (Otto de Greiff) from COLCIENCIAS. Tissue 278 collections were authorized by permits No. 004, 36, 2194, and 1177 granted by the Colombian 279 Ministry of Environment and Authority for Environmental Licenses (ANLA), 078-2003 from the 280 Peruvian National Insititute of Natural Resources, 002-012012 from the Nicaraguan Environment 281 and Natural Resource Ministry (MARENA), and SC/A-37-11 from the Panamanian Genetic 282 Resource Access Unit (UNARGEN). 


\section{Tables}

284 Table 1. Number of sequences analyzed per SCN4A segment and presence/amount of BTX in the

285 species of poison frogs used in this study. Numbers in parentheses represent new sequences added 286 for this study.

\begin{tabular}{|c|c|c|c|c|c|c|}
\hline \multirow[b]{2}{*}{ Species } & \multicolumn{4}{|c|}{ Number of Sequences } & \multirow{2}{*}{$\begin{array}{c}\text { BTX } \\
\text { Presence }\end{array}$} & \multirow[b]{2}{*}{ Citation } \\
\hline & DI & DII & DIII & DIV & & \\
\hline Allobates femoralis & 1 & 0 & 0 & 1 & $\mathrm{~N}$ & $\begin{array}{l}\text { (Daly et al. 1987; Darst et al. } \\
\text { 2005; Saporito and Grant 2018) }\end{array}$ \\
\hline Allobates talamancae & 1 & 0 & 0 & 1 & $\mathrm{~N}$ & (Daly et al. 1994) \\
\hline Allobates zaparo & 1 & 0 & 0 & 1 & $\mathrm{~N}$ & (Darst et al. 2005) \\
\hline Rheobates palmatus & $2(2)$ & 0 & 0 & $2(2)$ & NA & - \\
\hline Ameerega bilinguis & 1 & 1 & 1 & 1 & $\mathrm{~N}$ & (Daly et al. 2009) \\
\hline Ameerega hahneli & 1 & 0 & 0 & 1 & $\mathrm{~N}$ & (Daly et al. 2009) \\
\hline Ameerega parvula & 1 & 1 & 0 & 1 & $\mathrm{~N}$ & (Daly et al. 2009) \\
\hline Ameerega petersi & $1(1)$ & 0 & 0 & $1(1)$ & $\mathrm{N}$ & (Daly et al. 1987) \\
\hline Ameerega picta & $1(1)$ & 0 & 0 & $1(1)$ & $\mathrm{N}$ & (Daly et al. 1987, 2009) \\
\hline Ameerega trivittata & $1(1)$ & 0 & 0 & $1(1)$ & $\mathrm{N}$ & (Daly et al. 1987, 2009) \\
\hline Colostethus panamansis & 1 & 0 & 0 & 1 & $\mathrm{~N}$ & (Daly et al. 1994) \\
\hline Epipedobates anthonyi ${ }^{2}$ & 1 & 0 & 0 & 1 & $\mathrm{~N}$ & $\begin{array}{l}\text { (Daly et al. 1987; Spande et al. } \\
\text { 1992) }\end{array}$ \\
\hline Epipedobates boulengeri & 1 & 1 & 1 & 1 & $\mathrm{~N}$ & (Darst et al. 2005) \\
\hline $\begin{array}{c}\text { Epipedobates boulengeri } \\
\text { north }\end{array}$ & $3(3)$ & 0 & 0 & $3(3)$ & NA & - \\
\hline $\begin{array}{l}\text { Epipedobates } \\
\text { darwinwallacei }\end{array}$ & 1 & 0 & 0 & 1 & $\mathrm{~N}^{1}$ & (Santos and Cannatella 2011) \\
\hline Epipedobates machalilla & 1 & 0 & 0 & 1 & $\mathrm{~N}$ & (Santos and Cannatella 2011) \\
\hline Epipedobates tricolor $^{2}$ & 1 & 1 & 1 & 1 & $\mathrm{~N}$ & R.D. Tarvin pers com \\
\hline Silverstoneia nubicola & $1(1)$ & 0 & 0 & $1(1)$ & $\mathrm{NA}^{3}$ & - \\
\hline Silverstoneia cf erasmios & $2(2)$ & 0 & 0 & $2(2)$ & $\mathrm{NA}^{3}$ & - \\
\hline Andinobates bombetes & $2(2)$ & 0 & 0 & $2(2)$ & $\mathrm{N}$ & (Myers and Daly 1980) \\
\hline Andinobates fulguritus & $2(2)$ & 0 & 0 & $2(2)$ & $\mathrm{N}$ & (Daly et al. 1987) \\
\hline Dendrobates auratus & $17(2)$ & 0 & 0 & $2(2)$ & $\mathrm{N}$ & (Daly et al. 1987) \\
\hline Dendrobates tinctorius & 1 & 1 & 1 & 1 & $\mathrm{~N}$ & (Daly et al. 1987) \\
\hline Dendrobates truncatus & $2(2)$ & 0 & 0 & $2(2)$ & $\mathrm{N}$ & (Daly et al. 1987) \\
\hline Oophaga granulifera & 11 & 0 & 0 & 0 & $\mathrm{~N}$ & (Daly et al. 1987) \\
\hline Oophaga histrionica & $2(2)$ & 0 & 0 & $2(2)$ & $\mathrm{N}$ & $\begin{array}{c}\text { (Myers and Daly 1976; Daly et } \\
\text { al. 1987) }\end{array}$ \\
\hline Oophaga pumilio & $35(1)$ & 0 & 0 & $1(1)$ & $\mathrm{N}$ & $\begin{array}{c}\text { (Myers and Daly 1976; Daly et } \\
\text { al. 1987) }\end{array}$ \\
\hline $\begin{array}{l}\text { Phyllobates aurotaenia } \\
\text { north }\end{array}$ & $6(6)$ & 0 & 0 & $6(6)$ & Y & $\begin{array}{l}\text { (Märki and Witkop 1963; Daly et } \\
\text { al. 1965) }\end{array}$ \\
\hline
\end{tabular}


bioRxiv preprint doi: https://doi.org/10.1101/460865; this version posted November 3, 2018. The copyright holder for this preprint (which was not certified by peer review) is the author/funder, who has granted bioRxiv a license to display the preprint in perpetuity. It is made available under aCC-BY-NC-ND 4.0 International license.

\begin{tabular}{|c|c|c|c|c|c|c|}
\hline $\begin{array}{l}\text { Phyllobates aurotaenia } \\
\text { south }\end{array}$ & $3(3)$ & 0 & 0 & $3(3)$ & NA & - \\
\hline Phyllobates bicolor & $6(6)$ & $1(1)$ & $1(1)$ & $6(6)$ & $\mathrm{Y}$ & (Myers et al. 1978) \\
\hline Phyllobates lugubris & $5(5)$ & 0 & 0 & $5(5)$ & $\mathrm{Y}$ & $\begin{array}{l}\text { (Myers et al. 1978; Daly et al. } \\
\text { 1987) }\end{array}$ \\
\hline Phyllobates terribilis & $14(13)$ & 1 & $13(13)$ & $14(14)$ & $\mathrm{Y}$ & (Myers et al. 1978) \\
\hline Phyllobates vittatus & $2(2)$ & 0 & 0 & $2(2)$ & $\mathrm{Y}$ & $\begin{array}{l}\text { (Myers et al. 1978; Daly et al. } \\
\text { 1987) }\end{array}$ \\
\hline Ranitomeya toraro & $2(2)$ & 0 & 0 & $2(2)$ & NA & - \\
\hline $\begin{array}{c}\text { Ranitomeya } \\
\text { ventrimaculata }\end{array}$ & $1(1)$ & 0 & 0 & $1(1)$ & $\mathrm{N}$ & (Daly et al. 1987) \\
\hline Hyloxalus italoi & 1 & 1 & 1 & 1 & NA & - \\
\hline Hyloxalus nexipus & 1 & 1 & 1 & 1 & $\mathrm{~N}$ & (Santos and Cannatella 2011) \\
\hline Mantella aurantiaca & 1 & 1 & 1 & 1 & $\mathrm{~N}$ & $\begin{array}{l}\text { (Garraffo et al. 1993; Daly et al. } \\
\text { 1996) }\end{array}$ \\
\hline
\end{tabular}

$287 \quad{ }^{1}$ Refered to as Epipedobates sp. F by Santos and Cannatella (2011)

$288{ }^{2}$ Although Spande et al (1992) report an alkaloid profile for E. tricolor, based on the localities reported it is most likely 289 that the actual species used was E. anthonyi (Graham et al. 2004).

$290{ }^{3}$ The only chemical analysis of skin extracts from Silverstoneia species available in the literature (to our knowledge)

291 revealed a complete absence of alkaloids or Tetrodotoxin in S. flotator (Mebs et al. 2018). 


\section{Figures}

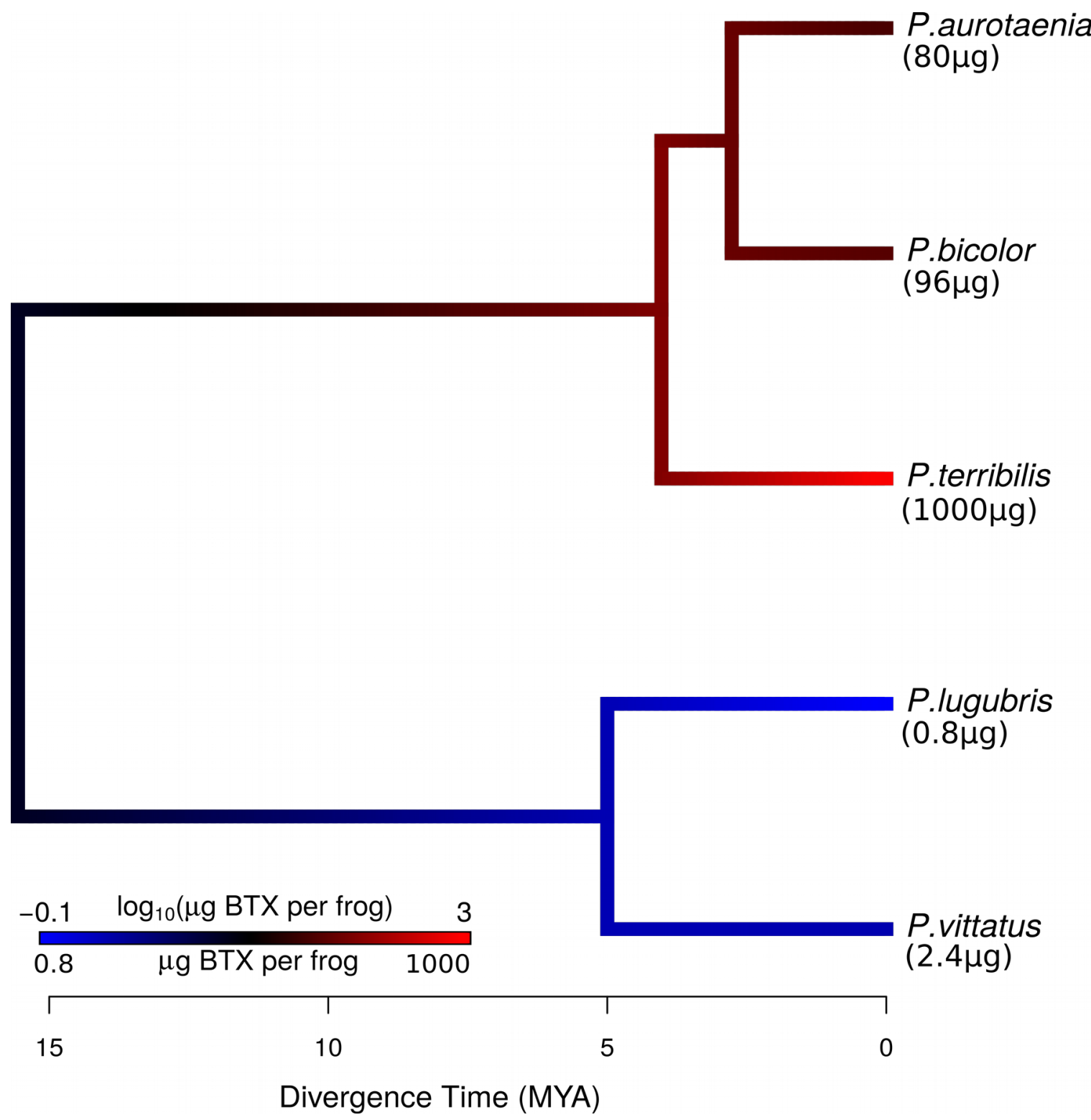

293 Figure 1. Phylogenetic relationships and average levels of cutaneous BTX per frog among 294 Phyllobates species, estimated from pooled batches of frog skins, as presented in Table 2 of Daly et 295 al. (1987). Branches were colored based on a maximum likelihood ancestral state reconstruction 296 under Brownian Motion using the approach of Revell (2013; Method 2). The topology follows 297 Grant et al. (2017), and divergence times were obtained from the TimeTree portal (Kumar et al. 298 2017). Numbers above the color bar are in $\log _{10}$ units, whereas those below the bar are in standard 299 units. 


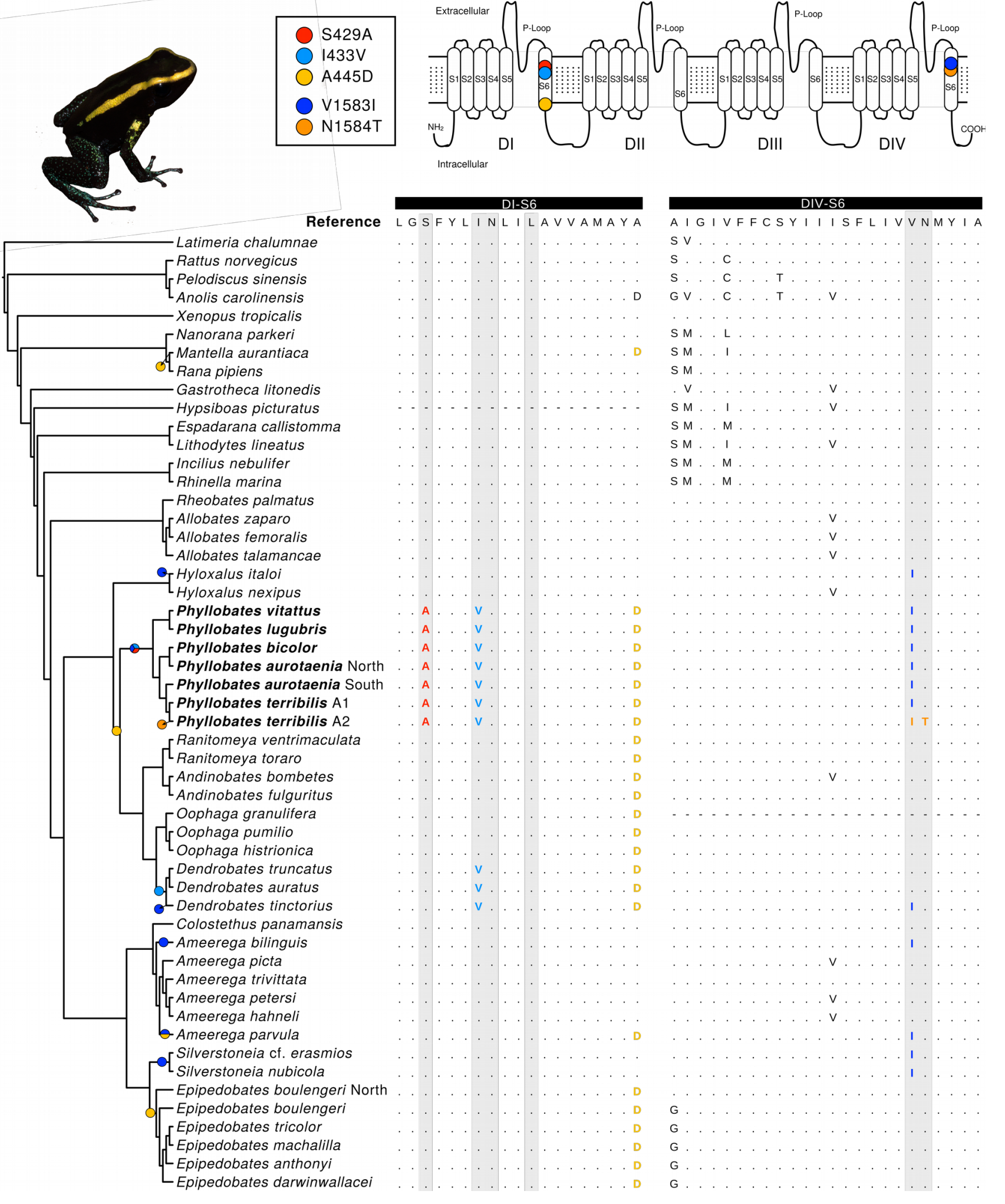

300 Figure 2. Amino acid sequences and ancestral reconstructions of the DI and DIV S6 segments of

301 dendrobatids and other frogs. The reference sequence corresponds to the reconstructed ancestral

302 frog sequence. The location of substitutions potentially important for autoresistance is indicated on

303 the $\mathrm{Na}_{\mathrm{v}} 1.4$ schematic above the alignment, and the origin of each substitution is indicated on the

304 corresponding branch. Sites known to be involved in BTX binding (Table S4) are shaded in grey. 
305 The topology follows Grant et al. (2017) and Pyron and Wiens (2011), and branch lengths are not

306 meaningful. Non-anuran sequences (i.e. coelacanth, rat, turtle, and anole) are only shown for

307 comparison, and were not used in analyses.

A.

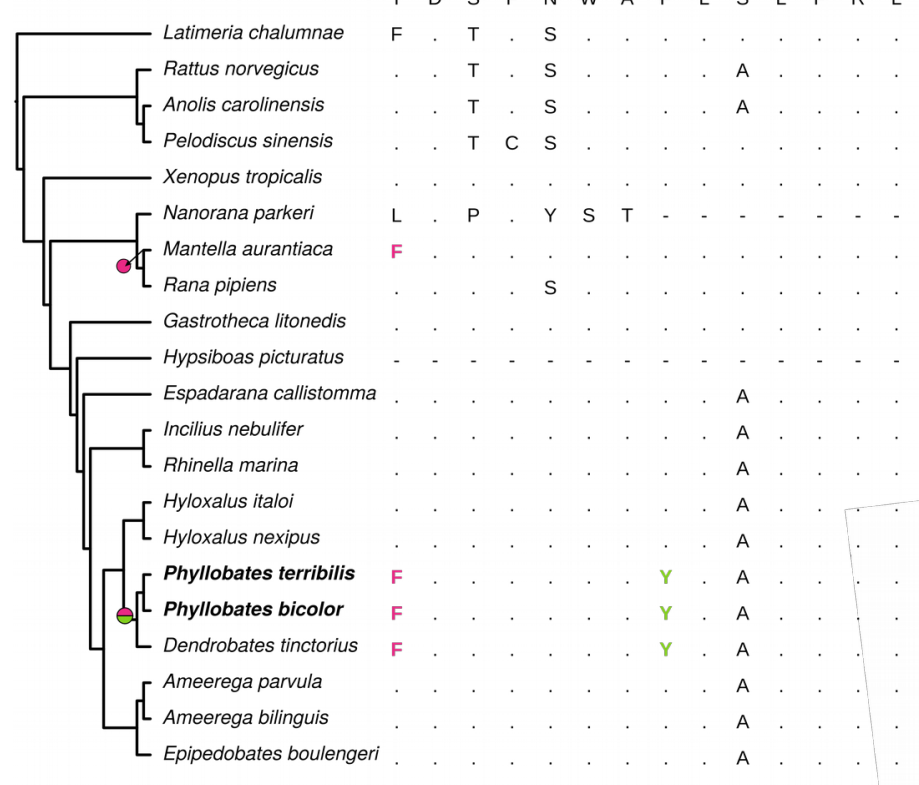

c.

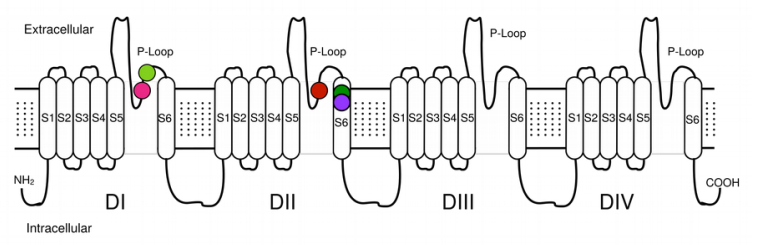

\begin{tabular}{|lr|}
\hline Y383F $O V 748 I$ & V774T \\
F390Y & M777L \\
\hline
\end{tabular}
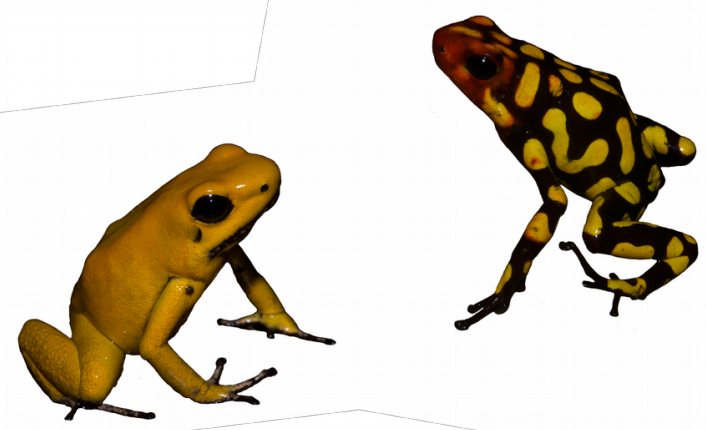

B.

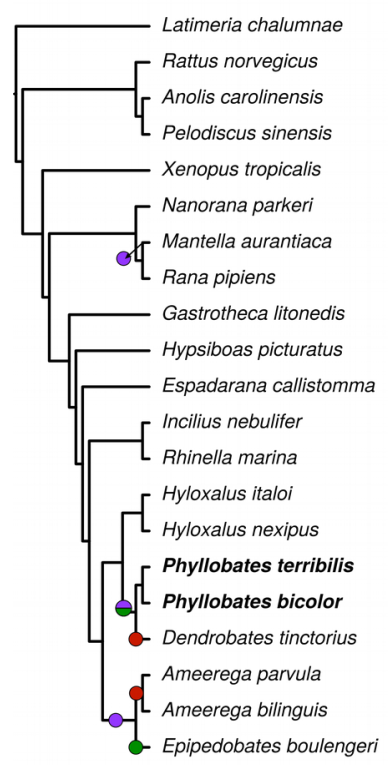

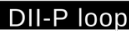

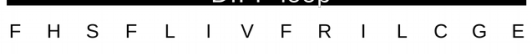

. A

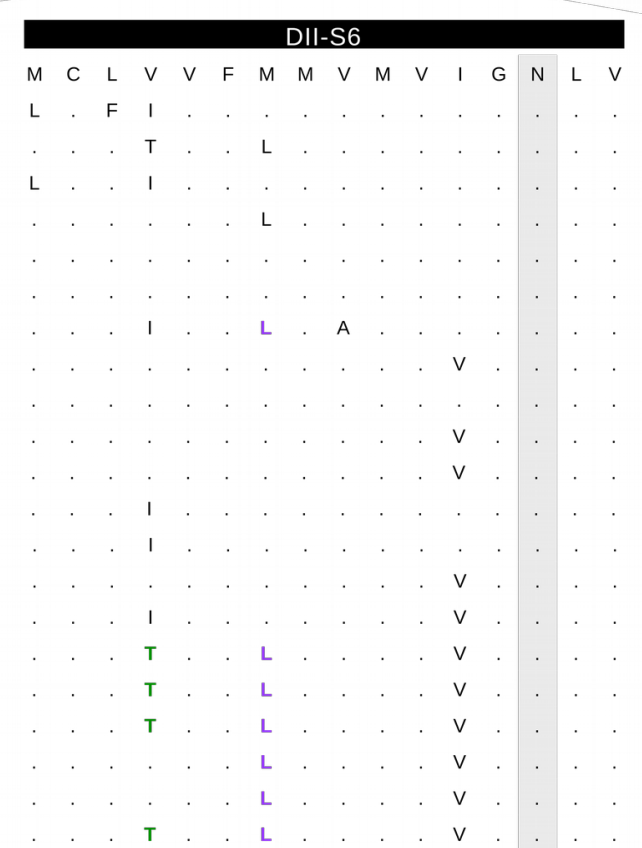

308 Figure 3. Amino acid sequences and ancestral reconstructions of the DI P-loop (A) and the DII P-

309 loop and S6 segments (B). The locations and evolutionary origins of mutations are shown in panel

$310 \mathrm{C}$ and on the phylogeny. The topology and shading are as in Figure 2. 


\section{References}

312

313

Albuquerque, E. X., J. E. Warnick, F. M. Sansone, and J. W. Daly. 1973. The pharmacology of batrachotoxin. V. A comparative study of membrane properties and the effect of batrachotoxin on sartorius muscles of the frogs Phyllobates aurotaenia and Rana pipiens. J. Pharmacol. Exp. Ther. 184:129-315.

Arce, F., and J. T. Rengifo. 2013. Dieta de Phyllobates aurotaenia y Oophaga histrionica (Anura: Dendrobatidae) en el municipio del Alto Baudó, Chocó, Colombia. Acta Zool. Mex. 29:255268.

Backx, P., D. Yue, J. Lawrence, E. Marban, and G. Tomaselli. 1992. Molecular localization of an ion-binding site within the pore of mammalian sodium channels. Science (80-. ). 257:248-251.

Bolger, A. M., M. Lohse, and B. Usadel. 2014. Trimmomatic: A flexible trimmer for Illumina sequence data. Bioinformatics 30:2114-2120.

Brodie III, E. D., and E. D. Brodie Jr. 1999. Costs of exploiting poisonous prey: evolutionary tradeoffs in a predator-prey arms race. Evolution (N. Y). 53:626-631.

Brodie Jr., E. D., B. J. Ridenhour, and E. D. Brodie III. 2002. The evolutionary response of predators to dangerous prey: Hotspots and coldspots in the geographic mosaic of coevolution between garter snakes and newts. Evolution (N. Y). 56:2067-2082.

Caldwell, J. P. 1996. The evolution of myrmecophagy and its correlates in poison frogs (Family Dendrobatidae). J. Zool. 240:75-101. Blackwell Publishing Ltd.

Chiamvimonvat, N., M. T. Pérez-García, G. F. Tomaselli, and E. Marban. 1996. Control of ion flux and selectivity by negatively charged residues in the outer mouth of rat sodium channels. J. Physiol. 491:51-59.

Christenson, M. K., A. J. Trease, L.-P. Potluri, A. J. Jezewski, V. M. Davis, L. a. Knight, A. S. Kolok, and P. H. Davis. 2014. De novo Assembly and analysis of the Northern Leopard Frog Rana pipiens transcriptome. J. Genomics 2:141-149.

Daly, J. W. 1998. Thirty years of discovering arthropod alkaloids in amphibian skin. J. Nat. Prod. 61:162-172. Laboratory of Bioorganic Chemistry, National Institute of Diabetes and Digestive and Kidney Diseases, National Institutes of Health, Bethesda, Maryland 20892, USA.

Daly, J. W., N. R. Andriamaharavo, M. Andriantsiferana, and C. W. Myers. 1996. Madagascan Poison Frogs (Mantella) and Their Skin Alkaloids. Am. Museum Novit. 3177:34.

Daly, J. W., F. Gusovsky, C. W. Myers, M. Yotsu-Yamashita, and T. Yasumoto. 1994. First occurrence of tetrodotoxin in a dendrobatid frog (Colostethus inguinalis), with further reports for the bufonid genus Atelopus. Toxicon 32:279-285.

Daly, J. W., C. W. Myers, J. E. Warnick, and E. X. Albuquerque. 1980. Levels of batrachotoxin and lack of sensitivity to its action in poison-dart frogs (Phyllobates). Science (80-. ). 208:13831385. 
Daly, J. W., C. W. Myers, and N. Whittaker. 1987. Further classification of skin alkaloids from neotropical poison frogs (dendrobatidae), with a general survey of toxic/noxious substances in the amphibia. Toxicon 25:1023-1095. Elsevier Ltd.

Daly, J. W., T. F. Spande, and H. M. Garraffo. 2005. Alkaloids from amphibian skin: A tabulation of over eight-hundred compounds. J. Nat. Prod. 68:1556-1575.

Daly, J. W., N. Ware, R. A. Saporito, T. F. Spande, and H. M. Garraffo. 2009. Nmethyldecahydroquinolines: An unexpected class of alkaloids from Amazonian poison frogs (Dendrobatidae). J. Nat. Prod. 72:1110-1114.

Daly, J. W., B. Witkop, P. Bommer, and K. Biemann. 1965. Batrachotoxin. The active principle of the Colombian arrow poison frog, Phyllobates bicolor. J. Am. Chem. Soc. 87:124-126. American Chemical Society.

Darriba, D., G. L. Taboada, R. Doallo, and D. Posada. 2012. jModelTest 2: More models, new heuristics and parallel computing. Nat Meth 9:772. Nature Publishing Group.

Darriba, D., G. L. Taboada, R. Doallo, and D. Posada. 2011. ProtTest 3: Fast selection of best-fit models of protein evolution. Bioinformatics 27:1164-1165.

Darst, C. R., P. A. Menéndez-Guerrero, L. A. Coloma, and D. C. Cannatella. 2005. Evolution of dietary specialization and chemical defense in poison frogs (Dendrobatidae): a comparative analysis. Am. Nat. 165:56-69. Section of Integrative Biology, Texas Memorial Museum, University of Texas, Austin, Texas 78712, USA. catdarst@utexas.edu.

Dean, A. M., and J. W. Thornton. 2007. Mechanistic approaches to the study of evolution: the functional synthesis. Nat. Rev. Genet. 8:675-688. Nature Publishing Group.

Dobler, S., G. Petschenka, and H. Pankoke. 2011. Coping with toxic plant compounds - The insect's perspective on iridoid glycosides and cardenolides. Phytochemistry 72:1593-1604. Elsevier Ltd.

Edgar, R. C. 2004. MUSCLE: multiple sequence alignment with high accuracy and high throughput. Nucleic Acids Res. 32:1792-1797.

Edmunds, M. 1974. Defence in animals : a survey of anti-predator defences. Longman, Burnt Mill.

Favre, I., E. Moczydlowski, and L. Schild. 1996. On the structural basis for ionic selectivity among $\mathrm{Na}+, \mathrm{K}+$, and $\mathrm{Ca} 2+$ in the voltage-gated sodium channel. Biophys. J. 71:3110-3125.

Feldman, C. R., E. D. Brodie Jr., E. D. Brodie III, and M. E. Pfrender. 2012. Constraint shapes convergence in tetrodotoxin-resistant sodium channels of snakes. Proc. Natl. Acad. Sci. 109:4556-4561.

Garraffo, H. M., J. Caceres, J. W. Daly, T. F. Spande, N. R. Andriamaharavo, and M. Andriantsiferana. 1993. Alkaloids in madagascan frogs (Mantella): Pumiliotoxins, indolizidines, quinolizidines, and pyrrolizidines. J. Nat. Prod. 56:1016-1038.

Gassmann, A. J., Y. Carrière, and B. E. Tabashnik. 2009. Fitness costs of insect resistance to Bacillus thuringiensis. Annu. Rev. Entomol. 54:147-163. 
Geffeney, S. L., E. Fujimoto, E. D. Brodie III, E. D. Brodie Jr., and P. C. Ruben. 2005. Evolutionary diversification of TTX-resistant sodium channels in a predator-prey interaction. Nature 434:759-63. Nature Publishing Group.

Grabherr, M. G., B. J. Haas, M. Yassour, J. Z. Levin, D. a Thompson, I. Amit, X. Adiconis, L. Fan, R. Raychowdhury, Q. Zeng, Z. Chen, E. Mauceli, N. Hacohen, A. Gnirke, N. Rhind, F. di Palma, B. W. Birren, C. Nusbaum, K. Lindblad-Toh, N. Friedman, and A. Regev. 2011. Fulllength transcriptome assembly from RNA-Seq data without a reference genome. Nat. Biotechnol. 29:644-652.

Graham, C. H., S. R. Ron, J. C. Santos, C. J. Schneider, and C. Moritz. 2004. Integrating phylogenetics and environmental niche models to explore speciation mechanisms in dendrobatid frogs. Evolution (N. Y). 58:1781-1793. Society for the Study of Evolution, Museum of Vertebrate Zoology, University of California, Berkeley, California 94720, USA. cgraham@life.bio.sunysb.edu.

Grant, T., M. Rada, M. Anganoy-Criollo, A. Batista, P. H. Dias, A. M. Jeckel, D. J. Machado, and J. V. Rueda-Almonacid. 2017. Phylogenetic systematics of Dart-Poison frogs and their relatives revisited (Anura: Dendrobatoidea). South Am. J. Herpetol. 12:S1-S90.

Groeters, F. R., B. E. Tabashnik, N. Finson, and M. W. Johnson. 1994. Fitness Costs of Resistance to Bacillus thuringiensis in the Diamondback Moth (Plutella xylostella). Evolution (N. Y). 48:197.

Guindon, S., J. F. Dufayard, V. Lefort, M. Anisimova, W. Hordijk, and O. Gascuel. 2010. New algorithms and methods to estimate maximum-likelihood phylogenies: Assessing the performance of PhyML 3.0. Syst. Biol. 59:307-321.

Guindon, S., and O. Gascuel. 2003. A simple, fast, and accurate algorithm to estimate large phylogenies by maximum likelihood. Syst Biol 52:696-704. LIRMM, CNRS, 161 Rue Ada, 34392, Montpellier Cedex 5, France.

Hanifin, C. T., and W. F. Gilly. 2015. Evolutionary history of a complex adaptation: Tetrodotoxin resistance in salamanders. Evolution (N. Y). 69:232-244. Society for the Study of Evolution.

Kumar, S., G. Stecher, M. Suleski, and S. B. Hedges. 2017. TimeTree: A Resource for Timelines, Timetrees, and Divergence Times. Mol. Biol. Evol. 34:1812-1819.

Lee, C. H., D. K. Jones, C. Ahern, M. F. Sarhan, and P. C. Ruben. 2011. Biophysical costs associated with tetrodotoxin resistance in the sodium channel pore of the garter snake, Thamnophis sirtalis. J. Comp. Physiol. A Neuroethol. Sensory, Neural, Behav. Physiol. 197:33-43.

Märki, F., and B. Witkop. 1963. The venom of the Colombian arrow poison frog Phyllobates bicolor. Experientia 19:329-338.

Mebs, D. 2001. Toxicity in animals. Trends in evolution? Toxicon 39:87-96.

Mebs, D., M. Yotsu-Yamashita, W. Pogoda, J. Vargas Alvarez, R. Ernst, G. Köhler, and S. W. Toennes. 2018. Lack of alkaloids and tetrodotoxin in the neotropical frogs Allobates spp. (Aromobatidae) and Silverstoneia flotator (Dendrobatidae). Toxicon 152:103-105. 
Myers, C. W., and J. W. Daly. 1976. Preliminary evaluation of skin toxins and vocalizations in taxonomic and evolutionary studies of poison-dart frogs (Dendrobatidae). Bull. Am. Museum Nat. Hist. 157:173-262.

Myers, C. W., and J. W. Daly. 1980. Taxonomy and ecology of Dendrobates bombetes, a new Andean poison frog with new skin toxins. Am. Museum Novit. 2692:1-23.

Myers, C. W., J. W. Daly, and B. Malkin. 1978. A dangerously toxic new frog (Phyllobates) used by Emberá Indians of western Colombia, with discussion of blowgun fabrication and dart poisoning. Bull. Am. Museum Nat. Hist. 161:307-366.

Osorio, D., L. Valenzuel, C. Bermudez-Rivas, and S. Castaño. 2015. Descripción de la dieta de una población de Oophaga histrionica (Athesphatanura: Dendrobatidae) en un enclave seco del Valle del Cauca, Colombia. Rev. Biodivers. Neotrop. 5:29.

Pérez-García, M. T., N. Chiamvimonvat, E. Marban, and G. F. Tomaselli. 1996. Structure of the sodium channel pore revealed by serial cysteine mutagenesis. Proc. Natl. Acad. Sci. U. S. A. 93:300-4.

Revell, L. J. 2013. Two new graphical methods for mapping trait evolution on phylogenies. Methods Ecol. Evol. 4:754-759.

Richardson, M. F., F. Sequeira, D. Selechnik, M. Carneiro, M. Vallinoto, J. G. Reid, A. J. West, M. R. Crossland, R. Shine, and L. A. Rollins. 2017. Improving amphibian genomic resources: a multi-tissue reference transcriptome of an iconic invader. Gigascience, doi: 10.1093/gigascience/gix114.

Rogers, R. L., L. Zhou, C. Chu, R. Márquez, A. Corl, T. Linderoth, L. Freeborn, M. D. MacManes, Z. Xiong, J. Zheng, C. Guo, X. Xun, M. R. Kronforst, K. Summers, Y. Wu, H. Yang, C. L. Richards-Zawacki, G. Zhang, and R. Nielsen. 2018. Genomic takeover by transposable elements in the Strawberry poison frog. Mol. Biol. Evol., doi: 10.1093/molbev/msy185.

Santos, J. C., and D. C. Cannatella. 2011. Phenotypic integration emerges from aposematism and scale in poison frogs. Proc. Natl. Acad. Sci. 108:6175-6180.

Santos, J. C., L. A. Coloma, and D. C. Cannatella. 2003. Multiple, recurring origins of aposematism and diet specialization in poison frogs. Proc. Natl. Acad. Sci. U. S. A. 100:12792-12797. Univ Texas, Sect Integrat Biol C0930, Austin, TX 78712 USA.

Santos, J. C., R. D. Tarvin, and L. A. O’Connell. 2016. A Review of chemical defense in poison frogs (Dendrobatidae): Ecology, pharmacokinetics, and autoresistance. Pp. 305-337 in Chemical Signals in Vertebrates 13. Springer International Publishing, Cham.

Saporito, R. A., and T. Grant. 2018. Comment on Amézquita et al. (2017) “Conspicuousness, color resemblance, and toxicity in geographically diverging mimicry: The pan-Amazonian frog Allobates femoralis.” Evolution (N. Y). 72:1009-1014.

Silverstone, P. A. 1976. A revision of the poison-arrow frogs of the genus Phyllobates Bibron in Sagra (Family Dendrobatidae). Nat. Hist. Museum Los Angeles County, Sci. Bull. 27:1-53. Natural History Museum of Los Angeles County, Natural History Museum of Los Angeles County. 
Spande, T. F., H. M. Garraffo, M. W. Edwards, H. J. C. Yeh, L. Pannell, and J. W. Daly. 1992. Epibatidine: a novel (chloropyridyl)azabicycloheptane with potent analgesic activity from an Ecuadoran poison frog. J. Am. Chem. Soc. 114:3475-3478. American Chemical Society.

Stern, D. L., and V. Orgogozo. 2009. Is genetic evolution predictable? Science (80-. ). 323:746-751. Department of Ecology and Evolutionary Biology, Howard Hughes Medical Institute, Princeton University, Princeton, NJ 08544, USA. dstern@princeton.edu.

Strichartz, G., T. Rando, and G. K. Wang. 1987. An integrated view of the molecular toxinology of sodium channel gating in excitable cells. Annu. Rev. Neurosci. 10:237-267.

Sun, Y.-B., Z.-J. Xiong, X.-Y. Xiang, S.-P. Liu, W.-W. Zhou, X.-L. Tu, L. Zhong, L. Wang, D.-D. Wu, B.-L. Zhang, C.-L. Zhu, M.-M. Yang, H.-M. Chen, F. Li, L. Zhou, S.-H. Feng, C. Huang, G.-J. Zhang, D. Irwin, D. M. Hillis, R. W. Murphy, H.-M. Yang, J. Che, J. Wang, and Y.-P. Zhang. 2015. Whole-genome sequence of the Tibetan frog Nanorana parkeri and the comparative evolution of tetrapod genomes. Proc. Natl. Acad. Sci. 112:E1257-E1262.

Tarvin, R. D., C. M. Borghese, W. Sachs, J. C. Santos, Y. Lu, L. A. O’Connell, D. C. Cannatella, R. A. Harris, and H. H. Zakon. 2017a. Interacting amino acid replacements allow poison frogs to evolve epibatidine resistance. Science (80-. ). 357:1261-1266.

Tarvin, R. D., E. A. Powell, J. C. Santos, S. R. Ron, and D. C. Cannatella. 2017b. The birth of aposematism: High phenotypic divergence and low genetic diversity in a young clade of poison frogs. Mol. Phylogenet. Evol. 109:283-295. Elsevier Inc.

Tarvin, R. D., J. C. Santos, L. A. O’Connell, H. H. Zakon, and D. C. Cannatella. 2016. Convergent substitutions in a sodium channel suggest multiple origins of toxin resistance in poison frogs. Mol. Biol. Evol. 33:1068-1081.

Toft, C. A. 1981. Feeding Ecology of Panamanian Litter Anurans: Patterns in Diet and Foraging Mode. J. Herpetol. 15:139.

Tokuyama, T., J. Daly, B. Witkop, I. L. Karle, and J. Karle. 1968. The structure of batrachotoxinin A, a novel steroidal alkaloid from the Colombian arrow poison frog, Phyllobates aurotaenia. J. Am. Chem. Soc. 90:1917-1918. American Chemical Society.

Vences, M., J. Kosuch, R. Boistel, C. F. B. Haddad, E. La Marca, S. Lötters, and M. Veith. 2003. Convergent evolution of aposematic coloration in Neotropical poison frogs: a molecular phylogenetic perspective. Org. Divers. Evol. 3:215-226. Univ Amsterdam, Museum Zool, Inst Biodivers \& Ecosyst Dynam, NL-1090 GT Amsterdam, Netherlands.

Vendantham, V., and S. C. Cannon. 2000. Rapid and Slow Voltage-Dependent Conformational Changes in Segment IVS6 of Voltage-Gated Na+ Channels. Biophys. J. 78:2943-2958. Elsevier.

Wang, S.-Y., J. Mitchell, D. B. Tikhonov, B. S. Zhorov, and G. K. Wang. 2006. How batrachotoxin modifies the sodium channel permeation pathway: computer modeling and site-directed mutagenesis. Mol. Pharmacol. 69:788-795.

Wang, S.-Y., C. Nau, and G. K. Wang. 2000. Residues in Na+ channel D3-S6 segment modulate both batrachotoxin and local anesthetic affinities. Biophys. J. 79:1379-1387. Elsevier. 
Wang, S.-Y., D. B. Tikhonov, B. S. Zhorov, J. Mitchell, and G. K. Wang. 2007. Serine-401 as a batrachotoxin- and local anesthetic-sensing residue in the human cardiac $\mathrm{Na}+$ channel. Pflügers Arch. - Eur. J. Physiol. 454:277-287.

Wang, S.-Y., and G. K. Wang. 1999. Batrachotoxin-Resistant Na+ Channels Derived from Point Mutations in Transmembrane Segment D4-S6. Biophys. J. 76:3141-3149. Elsevier.

Wang, S.-Y., and G. K. Wang. 2017. Single rat muscle Na + channel mutation confers batrachotoxin autoresistance found in poison-dart frog Phyllobates terribilis. Proc. Natl. Acad. Sci. 201707873.

Wang, S. Y., M. Barile, and G. K. Wang. 2001. Disparate role of $\mathrm{Na}(+)$ channel D2-S6 residues in batrachotoxin and local anesthetic action. Mol. Pharmacol. 59:1100-1107.

Wang, S. Y., and G. K. Wang. 1998. Point mutations in segment I-S6 render voltage-gated Na+ channels resistant to batrachotoxin. Proc. Natl. Acad. Sci. U. S. A. 95:2653-2658.

Warnick, J. E., E. X. Alburquerque, R. Onur, S. E. Jansson, J. Daly, T. Tokuyama, and B. Wiktop. 1976. The pharmacology of batrachotoxin. VII. Structure-activity relationships and the effects of pH. J. Pharmacol. Exp. Ther. 193:232-245.

Wright, S. 1932. The roles of mutation, inbreeding, crossbreeding, and selection in evolution. Proc. Sixth Int. Congr. Genet. 1:356-366.

Yang, Z. 2007. PAML 4: Phylogenetic analysis by maximum likelihood. Mol. Biol. Evol. 24:15861591.

Yuan, M. L., and I. J. Wang. 2018. Sodium ion channel alkaloid resistance does not vary with toxicity in aposematic Dendrobates poison frogs: An examination of correlated trait evolution. PLoS One 13:e0194265.

Zhao, Y., V. Yarov-Yarovoy, T. Scheuer, and W. A. Catterall. 2004. A gating hinge in Na+ channels: A molecular switch for electrical signaling. Neuron 41:859-865.

Zhen, Y., M. L. Aardema, E. M. Medina, M. Schumer, and P. Andolfatto. 2012. Parallel molecular evolution in an herbivore community. Science (80-. ). 337:1634-1637.

Zhou, J., and L. Fritz. 1994. Okadaic acid antibody localizes to chloroplasts in the DSP-toxinproducing dinoflagellates Prorocentrum lima and Prorocentrum maculosum. Phycologia 33:455461. The International Phycological Society. 